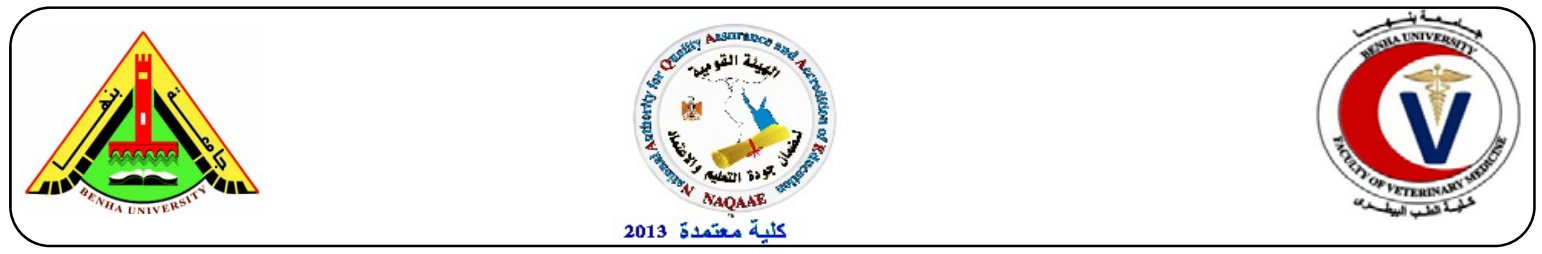

\title{
Biochemical study on the effect of cetyl trimethyl ammonium bromide surfactant coated spirulina zinc oxide nanocomposite as antimammary carcinogenesis in rats
}

Omayma, A. R. Abou Zaid ", Abdel-maksoud, A.H., Elsenosy, Y.A. and, Omnia, I .A.

${ }^{1}$ Department of Biochemistry, Faculty of Veterinary Medicine, Benha University, Egypt.

*1(omayma_ragab55@yahoo.com).

\begin{abstract}
A B S T R A C T
Breast cancer is one of the most cancers in women of developed and developing countries. The optimum management of which requires a multidisciplinary approach including the use of certain biochemical and histopathological markers. The effect of polysaccharide spirulina along zinc oxide nanoparticles on MNU induced mammary carcinogenesis was investigated in female Sprague rats. Injection of N-methyl N-Nitrosourea induced a significant increase in ALT, AST, Mammary MDA and serum NO levels. On other hand marked depletion in mammary GSH, CAT, SOD and GPx. These changes were confirmed by histopathological changes that observed after MNU intoxication. Administration of polysaccharide spirulina and $\mathrm{ZnO}$ nanoparticles was able to mitigate mammary carcinogenic damage induced by $\mathrm{MNU}$ as evidence to pronounced curative effect against lipid peroxidation, serum NO level and deviated enzymatic variables as well as maintained glutathione status, antioxidant enzymes in addition histopathological changes directed toward control. The results of the present study suggest that polysaccharide spirulina and $\mathrm{ZnO}$ nanoparticles have potential to exert curative effects against mammary carcinogenesis.
\end{abstract}

Keywords: Breast cancer, MNU, ZnO nanoparticles, Spirulina, CTAB.

$$
\text { (http://www.bvmj.bu.edu.eg) }
$$

(BVMJ-29(1): 170-182, 2015)

\section{INTRODUCTION}

$\mathrm{B}$ reast cancer is one of the most common cancers among women. With nearly a million new cases each year. It accounts for nearly $21 \%$ of all cancers among women worldwide (Parkin $\mathrm{DM}$ and Fernandez LMG, 2006), it is the second leading cause of cancer death after lung cancer (Dumitrescu RG and Cotarla I, 2005). Prevalence of breast carcinoma is high in Egypt and the cases of breast cancer constitute $29 \%$ of cancer cases treated at the national cancer institute. It is considered the most common cancer among Egyptian females representing $18.9 \%$ of total cancer cases (Omar S et al., 2003). One major reason is that many cancers are difficult to treat, mainly because the commonly used molecular drugs are unable to reach the diseased site or cannot reach the site without being structurally modified inside the organism (Ferrari M. et al., 2005). As a result, much effort is being devoted to the development of approaches that can directly target the cancer cells (Schrama D. et al., 2006). By focusing the treatment only on the cancerous cells, deleterious side effects can be avoided. One method of delivery is constituted by metallic nanoparticles. Metallic nanoparticles are inert in the body, but are able to selectively deliver their payload to the targeted cells when their surfaces are functionalized with antibodies specifically recognizing membrane proteins of the diseased cell. In addition, with the proper targeting moieties, metallic nanoparticles might even be able cross the 
Blood Brain Barrier (Nathanson D. and Mischel P., 2011). Additionally, by exploiting the intrinsic and drastically different properties of metallic nanoparticles and cells, targeted delivery will also yield diagnostic information, delivering exact information on the location and size of the tumor (Huang X. et al., 2006). Zinc oxide ( $\mathrm{ZnO})$ has special properties, such as high chemical activity, novel optical, mechanical, electromagnetic, thermodynamic, electrodynamics properties, and displays a wide spectrum of applications, including gaseous sensors (Tomchenko et al., 2003), fluorescent materials (Chen et al., 1995), photocatalysts (Marcì et al., 2001), and additives in many industrial products (Ghosh et al., 2000). Furthermore, $\mathrm{ZnO}$ is an environmentally friendly material, which is desirable especially for bio-applications, such as bioimaging and cancer detection (Wu et al., 2007). Therefore, there is a continuing search for better control and preventive methods in order to reduce cancer mortality and related side effects Many investigations are now being carried out to discover naturally occurring compounds, which can suppress or prevent the process of carcinogenesis (Thapliyal et al., 2002). Polysaccharides, a class of biopolymers naturally originated from plants or animals, have been widely studied in biotechnological and biomedical applications (Kumari A et al., 2010). Its inhibitory effect may be attributed to the repair of carcinogen- damaged DNA, and SP has been suggested as an efficient radical scavenger (Chamorro G. ET AL., 2004). Other studies have reported that the unique polysaccharides of SP enhance cell nucleus enzyme activity and potentiate the process of DNA repair (Kaji T ET AL., 2002). CTAB is a quaternary ammonium compound belonging to a group of small molecules known as delocalized lipophilic cations (DLCs). Because of their lipophilic nature and delocalized positive charge, DLCs can penetrate the hydrophobic barriers of plasma and mitochondrial membranes and accumulate in the mitochondria in response to the negative transmembrane potential, resulting in mitochondriotoxicity (Chen, 1988). The degree of glycolytic up-regulation also varies between different tumors, which might in part explain the differential sensitivity to CTAB among the various cancer cell lines. Head and neck cancers, which are often hypoxic, are commonly associated with high aerobic glycolytic activity and increased aggressiveness (Cohen et al., 2004; Isa et al., 2006), whereas the MCF7 breast and A549 lung cancer cells have relatively lower aerobic glucose consumption rates (Robey et al., 2005). More recently, surfactants have been found to have an effect on cell proliferation at concentrations well below those required for lysis of the plasma membrane. In vivo studies have revealed that some of these surfactants have antitumor activity (Tarnowski et al., 1978) and inhibit the development of tumor metastases (Silk and Sigman, 1972). The action of one halogenic quaternary ammonium compound on the in vitro proliferation of different lines of human cancer cells, indicate that halogenic quaternary ammonium present a potant growth inhibitory activity of different cancer cell lines. The presence of quaternary ammonium group, responsible for some alkylating effect (Gastaud et al., 1998). The presence of surfactant may lower the surface tension and increase the solubility of the drug with an organic solvent. Surfactants are alsooften used to stabilize micro-emulsions and suspensions into which drugs are dissolved. The presence of surfactants within drug product formulation may result in an compatibility with drug delivary technologies which relay upon well regulated hydration, dissolution and erosion of a matrix or coating to achieve controlled release. The influence of changes in $\mathrm{PH}$ within the gasterointestinal tract upon the bioavailability of pharmaceuticals is well documented (Michael et al., 2003). Doxorubicin (DOX) in particular is often the first choice to treat mammary cancer. 
Nevertheless, its use has been limited due to the rapid development of chemo resistance and cardiomyopathic side effects (Wang $\mathrm{J}$ et al., 2011). The therapeutic activity of DOX results from its intercalating into DNA, thereby inhibiting topoisomerase II and preventing DNA and RNA synthesis (Deavall DG et al., 2012). The main aim of this study was to investigate the possible protective and chemo-preventive effect of the novel nanocomoposites (Spirulina / Zinc oxide / CTAB) in inhibiting oxidative stress responses associated with MNUinduced breast carcinogenesis in rats, Through evaluation of the following biochemical serum and tissue parameters: Extent of oxidative stress was also assessed Mammary lipid peroxidation of LMalondialdehyde (MDA) and Serum levels of Nitric oxide (NO), Reduced Glutathione (GSH) and Activity of antioxidant enzymes (Catalase (CAT), Superoxide Dismutase (SOD), Glutathione Peroxidase (GPx)), in addition to activity of serum Alanine Aminotransferase (ALT), Aspartate Aminotransferase (AST) and histopathological changes were determined in mammary tissue.

\section{MATERIALS AND METHODS}

\subsection{Chemicals and antioxidants:}

MNU (purity 99\%) was manufactured by Sigma Chemical Co. (St. Louis, Mo, USA) and purchased from Schnelldorf, Germany through the Egyptian International Center for Import Cairo, Egypt. $\mathrm{ZnO}$ nanogard (purity $\sim 99 \%$ ) was manufactured by Sigma Chemical Co. (St. Louis, Mo, USA) and purchased from Schnelldorf, Germany through Alfa Acer, Egypt. Polysaccharide spirulina (purity $99 \%$ ) was manufactured by national research center, Al-Doky, Egypt. CTAB (purity $299 \%$ ) was manufactured by Sigma Chemical Co. (St. Louis, Mo, USA) and purchased from Schnelldorf, Germany through the Egyptian International Center for Import Cairo, Egypt. Doxorubicin hydrochloride (purity $\sim 99 \%$ ) was manufactured by Sigma
Chemical Co. (St. Louis, Mo, USA) and purchased from ALZA Corporation Bedford through the Egyptian International Center for Import Cairo, Egypt.

\subsection{Experimental animals:}

A total number of 96 virgin female albino rats, 4 weeks old and average body weight130-150gm. were used in the experimental investigation of this study, rats obtained from the Laboratory Animals Research Center, Faculty of Veterinary Medicine, Benha University, housed in separate wire mesh cages, exposed to good ventilation, humidity and to a 12-hr light dark cycle, and provided with a constant supply of standard pellet diet and fresh, clean drinking water ad libitum.

\subsection{Preparation and administration of dosage}

MNU was dissolved immediately prior to its use in $4 \mathrm{ml}, \mathrm{Nacl} 9 \%$ and acidified to $\mathrm{pH}$ 4 with acetic acid in such a way that each $\mathrm{ml}$ was containing $5 \mathrm{mg}$ of MNU and was administered to rats at the dose rat of $50 \mathrm{mg}$ $/ \mathrm{kg}$ body weight intra-peritoneal following all necessary safety and sterile precaution. After dissolving, The MNU was used within $20 \mathrm{~min}$. MNU injected i.p. at two doses after 50, 80 days of age (perse et al., 2009). Nano composite A (Spirulina $+\mathrm{CTAB}$ ) at dose of 12.59 $\mathrm{mg} / \mathrm{kg} . b . w t$ and Nano composite $\mathrm{C}($ Spirulina $+\mathrm{CTAB}+\mathrm{ZnO}$ ) at dose of 30 $\mathrm{mg} / \mathrm{kg} . \mathrm{b} . \mathrm{wt}$ dissolved in saline injected orally by stomach tube three times in a week for the end of experiment (18 $8^{\text {th }}$ weeks). Doxorubicin Received 33 mg /kg.b.w.t / i.p dissolved in physiological saline once a week for 4 weeks after the first experiment (14 ${ }^{\text {th }}$ weeks) (Radhakrishnan Padmavathi et al., 2006).

\subsection{Experimental design}

Rats were randomly divided into eight groups, 12 rat each and classified as following: (Group 1) served as control normal group NTBR (12 rats); (Group 2) Considered as control diseased group for comparison with two nano-composites 
protected groups .Rats injected with MNU at a dose of $(50 \mathrm{mg} / \mathrm{kg}$ b.wt. i.p. $)$ given at two doses at the 50 and 80 days 0 age, at 3 weeks interval for induction of mammary cancer. The rats were sacrificed $14^{\text {th }}$ weeks after the first dose of MNU; (Group 3) Considered as control diseased group for comparison with two nano-composites treated groups. Rats injected with MNU at a dose of $(50 \mathrm{mg} / \mathrm{kg}$ b.wt. i.p.) given at two doses at the 50 and 80 days $0 \mathrm{f}$ age , at 3 weeks interval for induction of mammary cancer. The rats were sacrificed $18^{\text {th }}$ weeks after the first dose of MNU; (Group 4) served as (spirulina + CTAB) protected group TBRP (Spirulina +CTAB) rats administered nano composite A 12,59 $\mathrm{mg} / \mathrm{kg}$.b.wt, daily) orally by stomach tube three times in a week for 14 weeks followed by induction of mammary carcinogenesis by MNU dose; (Group 4) served as (spirulina $+\mathrm{CTAB}+\mathrm{ZnO}$ ) protected group TBRP(Spirulina $+\mathrm{CTAB}+\mathrm{ZnO}) 12$ rats administered Nano composite C( Spirulina $+\mathrm{CTAB}+\mathrm{ZnO}$ ) at dose of $30 \mathrm{mg} / \mathrm{kg}$.b.wt orally by stomach tube three times in a week for 14 weeks; (Group 5) served as (spirulina + CTAB) treated group TBRT(Spirulina + CTAB)(12rats) administered with nano composite A $12,59 \mathrm{mg} / \mathrm{kg} . b . w t$, daily p.o) dissolved in saline injected orally by stomach tube three times in a week for 18 weeks followed by induction of mammary carcinogenesis by MNU dose $(50 \mathrm{mg} / \mathrm{kg}$ body, i.p); (Group 6) (spirulina + CTAB+ $\mathrm{ZnO}$ ) treated group TBRT (Spirulina + $\mathrm{CTAB}+\mathrm{ZnO})$ rats administered with Nano composite $\mathrm{C}$ ( Spirulina $+\mathrm{CTAB}+\mathrm{ZnO}$ ) at dose of $30 \mathrm{mg} / \mathrm{kg} . \mathrm{b} . w \mathrm{t}$ orally by stomach tube three times in a week for 18 weeks.; (Group 7) served as (Doxorubicin) treated group TBRT (DOX) rats treated with doxorubicin at a dose of $33 \mathrm{mg} / \mathrm{kg}$.b.w.t $/$ i.p once for 4weeks) after first experiment after 14 weeks.

\subsection{Sampling}

\subsubsection{Blood samples}

After overnight fasting, blood samples were divided into two parts one part were used immediately for measuring the activity of the following biochemical parameters: Nitric oxide (NO) levels, Alanine aminotransferase (ALT) activity, Aspartate aminotransferase (AST) activity, The second part of blood samples were collected in dry, clean test tubes and allowed to clot for $30 \mathrm{~min}$ and serum was separated by centrifugation at $3000 \mathrm{rpm}$ for $15 \mathrm{~min}$ at 4 ${ }^{\circ} \mathrm{c}$ and quickly frozen in a deep freezer at ($20{ }^{\circ} \mathrm{C}$ ) for subsequent biochemical analyses.

\subsubsection{Tissue specimen (mammary tissue)}

After finishing blood sampling, rats of each group were sacrificed by cervical decapitation The abdomen was opened and the mammary specimen was quickly removed and opened gently using a scrapper, cleaned by rinsing with ice-cold isotonic saline to remove any blood cells, then blotted between 2 filter papers. Then divided into two parts, part of them was homogenated and samples were prepared in ice- cold phosphate buffer $(0.1 \mathrm{M}, \mathrm{pH} 7.4)$ using a potter- Elvehjem homogenizer to give a $10 \%$ homogenates which were used for for estimation of mammary L-MDA, GPx, CAT, SOD and GSH. These tissue samples were quickly frozen in a deep freezer at $\left(-20{ }^{\circ} \mathrm{C}\right)$ for subsequent biochemical analyses. And the other part of mammary tissues were dissected and kept in $10 \%$ formalin for histopathological examination.

\subsection{Biochemical analysis:}

\subsubsection{Antioxidant activity \&Lipid peroxide determination:}

Mammary tissue GPx, SOD, CAT, GSH, MDA activity, serum nitric oxide level, ALT activity and AST activity were analyzed according to the methods described by (Paglia and Valentine, 1967), (Yoshikawa, 1972), (Sinha, 1972),(Beutler et al., 1963), (Yoshioka et al., 1979), (Montgomery and Dymock, 1961) and (Murray, 1984) respectively.

\subsubsection{Histopathological examination}


Determined according to the method described by (Banchroft et al., 2006).

\subsubsection{Statistical analysis}

The results were expressed as mean \pm SEM of 7 rats per group and statistical significance was evaluated by one way ANOVA using SPSS (version 10.0) program followed by the post hoc test, least significant difference (LSD). Values were considered statistically significant when $p<$ 0.05 .

\section{RESULTS}

The obtained data in table (1) in first experiment revealed a significant increase in L-MDA, NO, ALT, AST level and significant decreases in SOD, GPx, CAT activities and GSH level in mammary tissue homogenate in TBR group, when compared with control normal group. Treatment with TBRT(CTAB+Spirulina), TBRT(CTAB $+\mathrm{S}$ pirulina $+\mathrm{ZnO}$ ) resulted in significant decrease L-MDA, NO, ALT, AST level and significant increase in SOD, GPx, CAT activities and GSH level in mammary tissue homogenate in comparison with TBR group in second experiment. The obtained data in figures $(1,2,3,4)$ revealed histopathological changes that occur during the first experiment (after 14 weeks) as the following: the mammary sections of control rats (NTBR) showing no histopathological alteration and the normal histological structure of the acini and ducts as well as the adipose tissue in between (1), TBR mammary section showing hyperplasia as well as dysplasia with appearance of group of polar, disfigured, irregular arrangement with hyper chromatic nuclei cells occluded the ducts (2), TBRP(CTAB+Spirulina) mammary sections showing intact lining epithelium (3), TBRP (CTAB + Spirulina + $\mathrm{ZnO})$ mammary sections showing hyperplasia in the lining epithelium with polyps formation and cyctic dilation (4). Obtained data in figures $(5,6,7,8)$ revealed histopathological findings that occur during the second experiment (after 18 weeks) as the following: the mammary sections of TBR showing Groups of polar , pleomorphic and hyperchromatic nuclei cells with lose of the basement membrane (anaplastic cells ) were detected and replacing the normal histological structure of the acini and ducts (5), TBRT (CTAB+Spirulina) mammary sections showing The acini and ducts were histologically intact except few irregular arrangement of the lining epithelium on the basement membrane (6), TBRT $(\mathrm{CTAB}+$ Spirulina $+\mathrm{ZnO})$ mammary sections showing Hyperplasia with polyps formation as well as cystic dilatation were detected I $\mathrm{n}$ the duct (7), TBRT (DOX) mammary sections showing The epithelial cells of the acini and ducts system showed mild irregular arrangement in the basement membrane .

\section{DISCUSSION}

Breast cancer is one of the most common cancers in women. This is the reason why a lot of effort is currently focused on understanding the clinical significance of known markers, finding relationships between them and discovering new ones. All of this research has the aim of utilising better the drugs available for treatment and developing novel therapies based on new cancer models (Vincenzo 2006). Chemically-induced carcinogenesis in laboratory animals is widely used for conducting research on the biology of cancer (Tomatis L, 2006). N-methyl-Nnitrosourea (MNU)-induced mammary carcinogenesis in female rats is frequently used as an animal model for the investigation of breast carcinogenesis and the treatment of breast cancer in humans (Melancon $\mathrm{K}$ et al., 2005). On day 50, all rats were injected with 1-methyl-1nitrosourea (MNU) to induce mammary tumors. MNU has been widely used in rodent models to induce diverse mammary tumors that differ in type and location of 
Table (1): biochemical effect of nanocomposites (Spirulina/ Zinc oxide / CTAB) in tissue, serum of normal and MNU-induced mammary carcinogenesis in female rats.

\begin{tabular}{|c|c|c|c|c|c|c|c|c|}
\hline Group & $\begin{array}{c}\text { CAT } \\
\text { (K/gm tissue) }\end{array}$ & $\begin{array}{c}\text { SOD } \\
\text { (u/gm. tissue) }\end{array}$ & $\begin{array}{c}\mathrm{Gpx} \\
(\mathrm{mU} / \mathrm{gm} \\
\text { tissue) }\end{array}$ & $\begin{array}{c}\mathrm{GSH} \\
\text { (mg/gm } \\
\text { tissue) }\end{array}$ & $\begin{array}{c}\text { MDA } \\
\text { (nmol/gm } \\
\text { tissue) }\end{array}$ & $\begin{array}{c}\text { No } \\
(\mu \mathrm{mol} / \mathrm{L} \text { in } \\
\text { Serum })\end{array}$ & $\begin{array}{l}\text { ALT in } \\
\text { serum } \\
(\mathrm{U} / \mathrm{L})\end{array}$ & $\begin{array}{l}\text { AST in serum } \\
)((\mathrm{U} / \mathrm{L}\end{array}$ \\
\hline \multicolumn{9}{|l|}{$\begin{array}{l}\text { Experiment I (after } 14 \\
\text { weeks) }\end{array}$} \\
\hline \multirow{3}{*}{ NTBR } & $33.63^{\mathrm{a}}$ & $326.67^{\mathrm{a}}$ & $36.53^{\mathrm{a}}$ & $68.25^{\mathrm{a}}$ & $38,00^{\mathrm{b}}$ & $37.00^{\mathrm{c}}$ & $36.53^{c}$ & $80.00^{\mathrm{c}}$ \\
\hline & $\pm 1,38$ & $\pm 25,17$ &, \pm 81 &, \pm 011 & $\pm 10,00$ & $\pm 10,00$ &, \pm 81 & $\pm 10,00$ \\
\hline & $17.66^{\mathrm{d}}$ & $150.00^{\mathrm{c}}$ & $13.11^{\mathrm{d}}$ & $33.76^{\mathrm{d}}$ & $85.00^{\mathrm{c}}$ & $126.67^{\mathrm{a}}$ & $150,0^{\mathrm{a}}$ & $150,0^{\mathrm{a}}$ \\
\hline TBR &, \pm 67 & $\pm 10,00$ &, \pm 75 & $\pm 1,20$ & $\pm 3,00$ & $\pm 12,58$ & $\pm 20,00$ & $\pm 10,00$ \\
\hline TBRP(CTAB+SPIRULI & $25.83^{\mathrm{c}}$ & $240.00^{\mathrm{b}}$ & $22.51^{\mathrm{c}}$ & $51.00^{\mathrm{c}}$ & $40,00^{\mathrm{b}}$ & $45.33^{\mathrm{c}}$ & $130,0^{\mathrm{ab}} \pm 5,0$ & $70,0^{\mathrm{c}}$ \\
\hline $\mathrm{NA}+\mathrm{ZnO})$ &, \pm 67 & $\pm 10,00$ &, \pm 80 &, \pm 61 & $\pm 2,00$ & $\pm 15,28$ & 0 & $\pm 10,00$ \\
\hline \multirow{2}{*}{\multicolumn{9}{|c|}{$\begin{array}{l}\text { Experiment II (after } 18 \\
\text { weeks) }\end{array}$}} \\
\hline & & & & & & & & \\
\hline & $17.41^{\mathrm{c}}$ & $126.67^{\mathrm{c}}$ & $13.43^{\mathrm{c}}$ & $31.56^{\mathrm{c}}$ & $110,00^{\mathrm{a}}$ & $143.33^{\mathrm{a}}$ & $55,94^{\mathrm{c}}$ & $1500 .^{\mathrm{a}}$ \\
\hline$(\mathrm{CTAB}+$ SPIRULINA $+\mathrm{Z}$ & $28.39^{\mathrm{b}}$ & $240.00^{\mathrm{b}}$ & $23.71^{\mathrm{b}}$ & $52.94^{\mathrm{ab}}$ & $73,00^{\mathrm{c}}$ & $65.33^{c}$ & $68,25^{\mathrm{b}}$ & $120,0^{\mathrm{ab}}$ \\
\hline \multirow[t]{2}{*}{ nO) } &, \pm 59 & $\pm 40,00$ &, \pm 72 & $\pm 2,84$ & $\pm 3,00$ & $\pm 3,51$ &, \pm 11 & $\pm 10,00$ \\
\hline & $31.79^{\mathrm{a}}$ & $255.00^{\mathrm{ab}}$ & $24.59^{\mathrm{b}}$ & $50.73^{\mathrm{b}}$ & $55,00^{\mathrm{b}}$ & $60.00^{c}$ & $74,62^{\mathrm{a}}$ & $140,0^{\mathrm{a}}$ \\
\hline TBRT (DOX) & $\pm 1,31$ & $\pm 5,00$ &, \pm 44 & $\pm 12,51$ & $\pm 1,00$ & $\pm 10,10$ &, \pm 24 & $\pm 20,00$ \\
\hline$P$ value & $\leq .001$ & $\leq .001$ & $\leq .001$ & $\leq .01$ & $\leq .001$ & $\leq .001$ & $\leq .001$ & $\leq .05$ \\
\hline
\end{tabular}




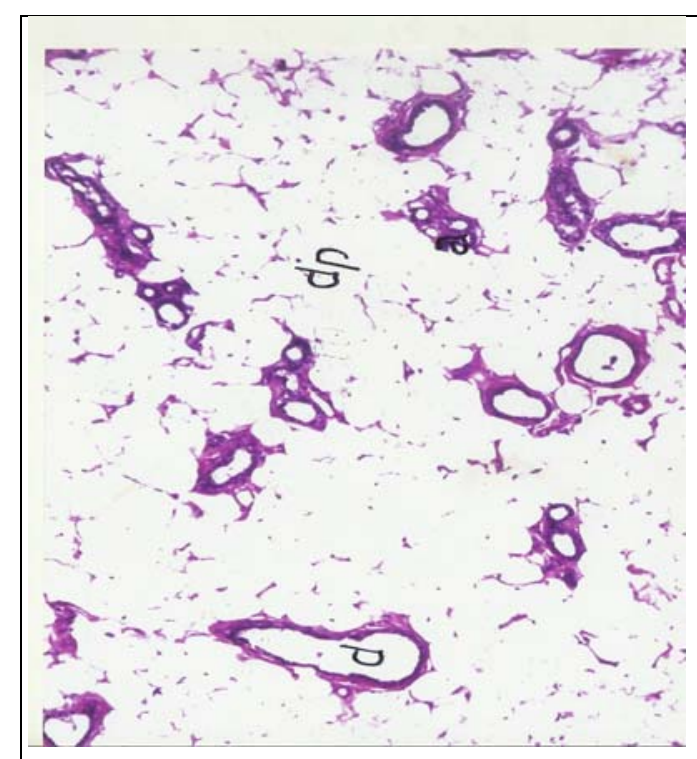

Fig (1): Mammary gland of NTBR showing normal histological structure of the acini (a(,ducts(d) and adipose tissue (dp) in between.

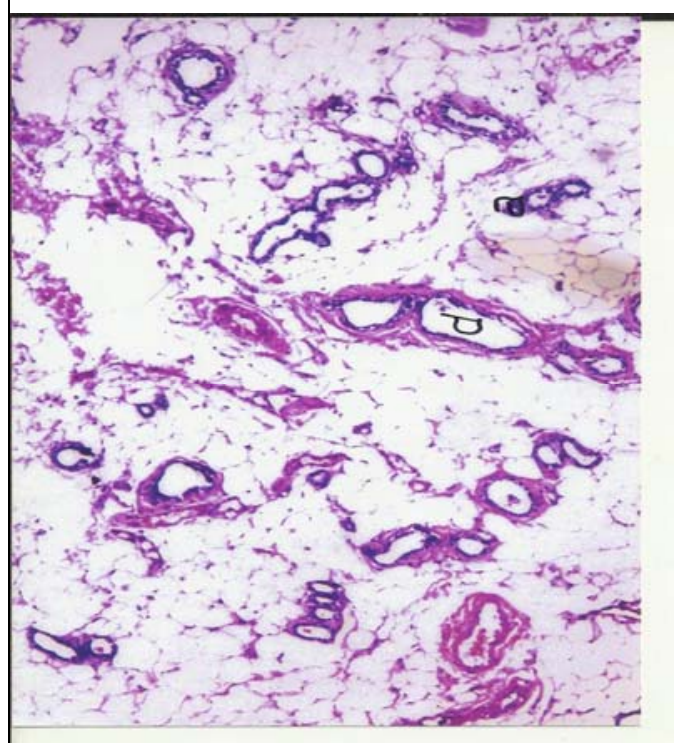

Fig (3): Mammary gland of TBRP(CTAB+Spirulina) showing intact lining epithelium of the acini (a) and ducts (d).

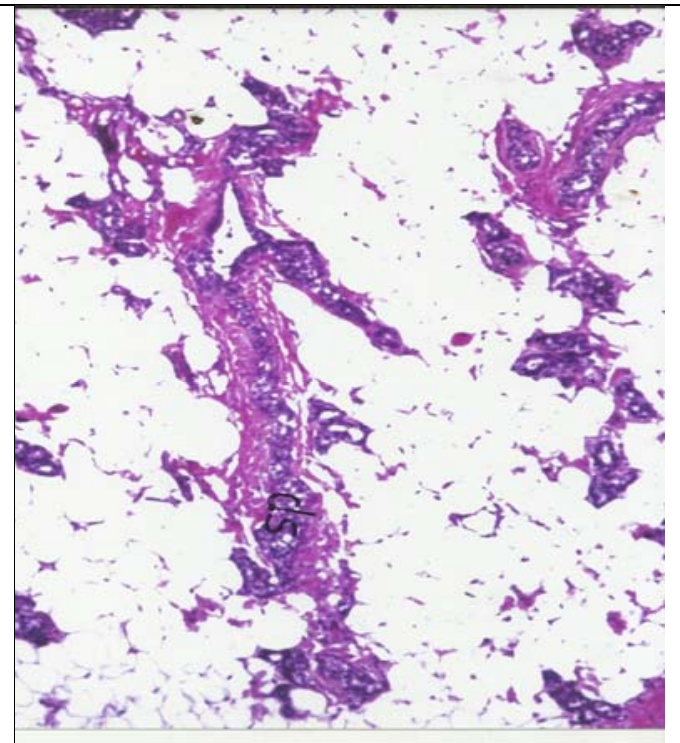

Fig (2): Mammary gland of TBR showing hyperplasia with dysplasia in lining ductal epithelium (ds) forming disfigured group of polarity cells.

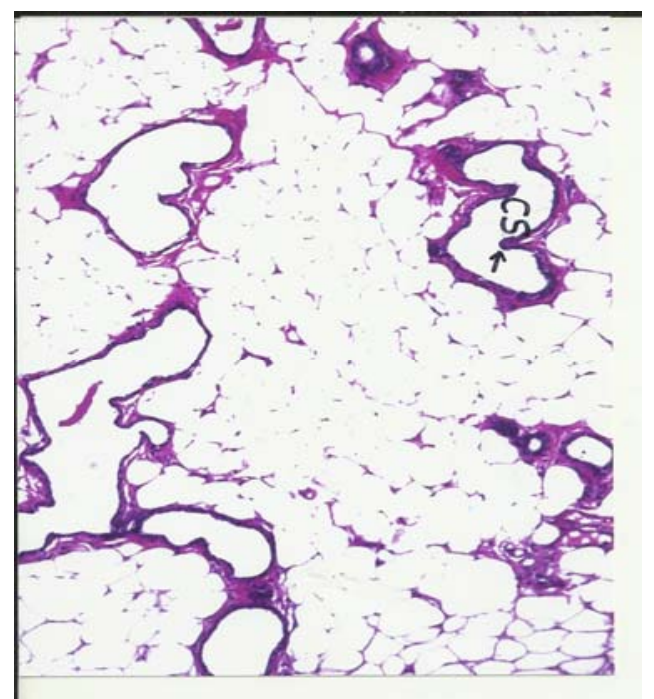

Fig (4): Mammary gland of TBRP $(\mathrm{CTAB}+$ Spirulina $+\mathrm{ZnO})$ showing hyperplasia with polyps formation (arrow) and cystic dilatation of ducts (cs). 


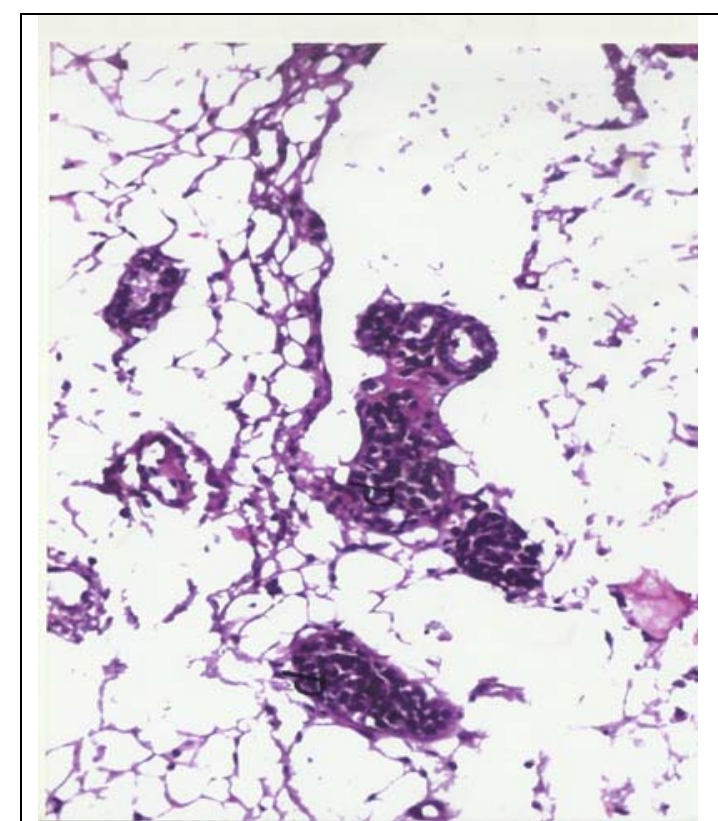

Fig (5): Mammary gland in TBR showing clumping of the lining epithelial cells in most ducts (d).

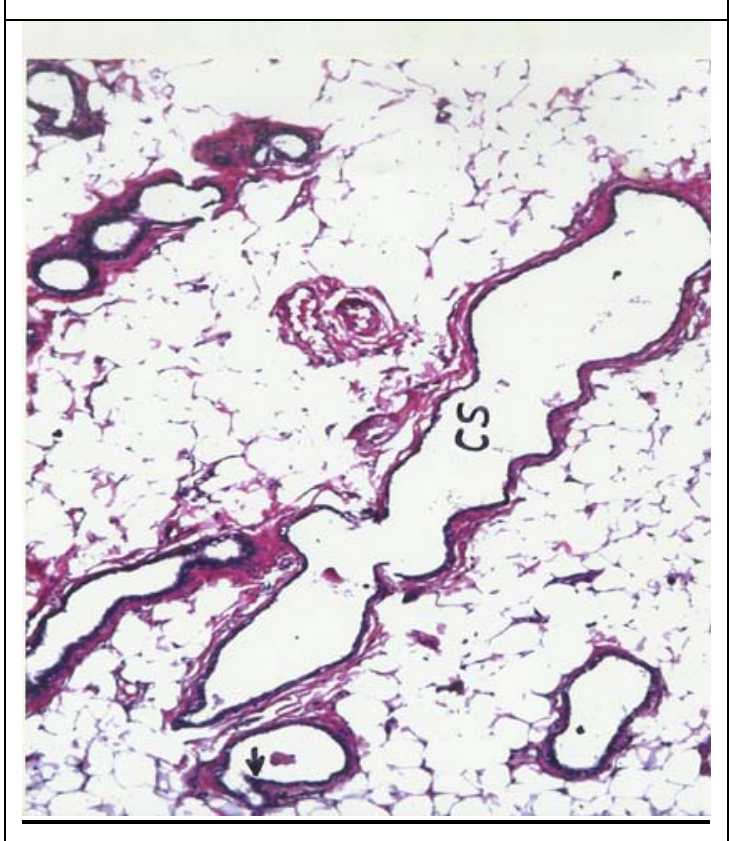

Fig (7):Mammary gland of TBRT $(\mathrm{CTAB}+$ Spirulina $+\mathrm{ZnO})$ showing ductal cystic dilatation (cs) with hyperplasia in lining epithelium and polyps formation (arrow).

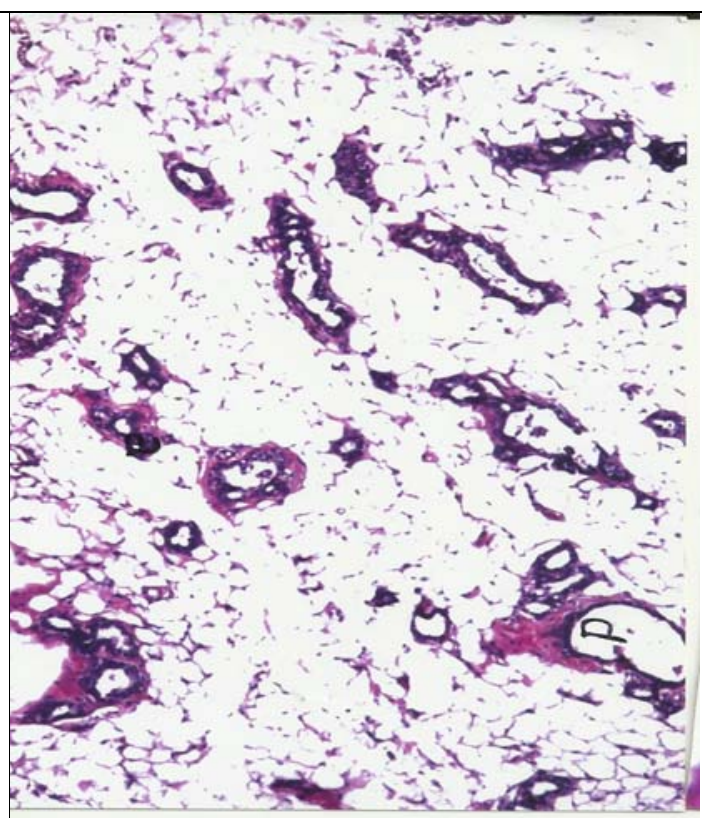

Fig (6): Mammary gland of TBRT $(\mathrm{CTAB}+$ Spirulina) showing the intact lumen and basement membrane in both duct and acini.

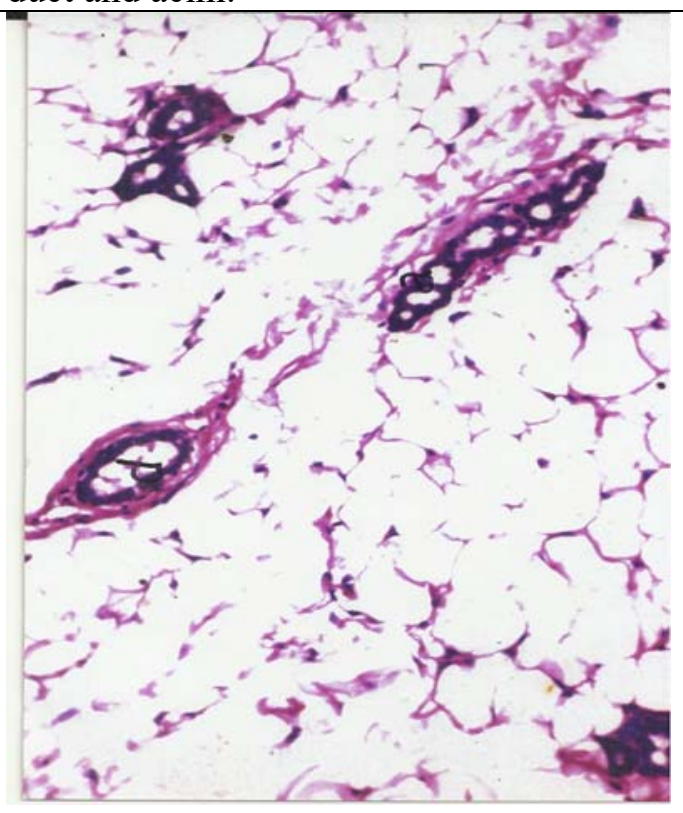

Fig (8):Mammary gland of TBRT (DOX) showing normal histological structure of the acini (a) and ducts (d). 
formation in the mammary gland for studying human breast cancer due to their similarities in hormone dependency. The carcinogenicity of MNU is due to its ability to induce a mutation in the H-ras oncogene (Lee et al. 2004). In the present study we investigated that administration of polysaccharide spirulina and $\mathrm{ZnO}$ nanoparticles was able to mitigate mammary carcinogenic damage induced by MNU and showed pronounced curative effect against lipid peroxidation, serum NO level and deviated enzymatic variables as well as maintained glutathione status , antioxidant enzymes and histopathological changes toward control levels. Administration of polysaccharide spirulina and $\mathrm{ZnO}$ was highly effective and protective against MNU induced mammary carcinogenesis. The obtained data in table (1) in first experiment revealed that a significant increase in L-MDA, NO, ALT, AST level and significant decreases in SOD, GPx, CAT activities and GSH level in mammary tissue homogenate in TBR group, when compared with control normal group. Treatment with TBRT (CTAB + Spirulina), TBRT (CTAB + Spirulina + $\mathrm{ZnO})$ resulted in significant decrease LMDA, NO, ALT, AST level. And significant increase in SOD, GPx, CAT activities and GSH level in mammary tissue homogenate in comparison with TBR group in second experiment.and these results are in agreement with those found by Mahmouda et al., (2012) who showed that the applications of nanoparticles have expanded, from solar cells to medicinal therapeutics and everything in between. The source of this development is the ability researchers now have to create, functionalize, and characterize particles better than ever before. Categories of nanoparticles include liposomes, dendritic particles, metallic particles, and polymers. Each of these categories has advantages and disadvantages. For example, liposomes are more easily absorbed by cells, while metallic nanoparticles, on their own, do not elicit adverse reactions within the body
(Pissuwana et al., 2006). As such, different types of nanoparticles are being explored as possible treatments for various types of cancers in an effort to develop more effective cancer therapeutics (ChoK. et al., 2008). The mechanisms of cytotoxicity from $\mathrm{ZnO}$ nanoparticles are not completely understood, but generation of reactive oxygen species (ROS) is believed to be a major component. When nanoparticles interact with cells, cellular defense mechanisms are activated to minimize damage. However, if ROS production exceeds the anti-oxidative defensive capacity of the cell, it results in oxidative damage of biomolecules, which can lead to cell death (Ryter SW et al., 2007). Lee et al., (2003) revealed that Zinc is important to cell proliferation; however, it accumulates in mammary tumors and supports tumor growth in one-study twenty-one-day old female rats were assigned to a low-zinc, an adequate-zinc, or ad libitum control groups. Results indicated low-zinc intake suppressed MNU-induced tumor incidence, tumor numbers and tumor multiplicity. Geraki and Farquharson (2001) analyzed zinc concentration in breast tissue samples coming from biopsies, mastectomies or breast reduction surgeries. Samples were grouped as 10 normal and 14 pathological, which included benign changes, carcinomas and fibroademomas. These measurements suggested significant elevation of zinc in the pathological tissues compared to normal tissues. In addition, Siddiqui et al showed that blood zinc was significantly higher in malignant cases than in those of benign and control (Siddiqui et al. 2006). These studies reveal that zinc accumulates in diseased samples compared to healthy samples. It is not known if the uncontrolled growth of cells in the tumor tissues accumulate more zinc to cope with the demands of the excessive dividing of the cells or if these metals play a role in tumorgensis.

There is a continuing search for better control and preventive methods in order to reduce cancer mortality and related side effects Many investigations are now being 
carried out to discover naturally occurring compounds, which can suppress or prevent the process of carcinogenesis (Thapliyal et al., 2002).Recent reports have demonstrated anti-oxidant, anti-inflammatory, antiproliferative and pro-apoptotic effects of various phytochemicals (Mehta RG et al., 2010) Moreover, the pro-apoptotic and antiproliferative effects of phytochemicals indicate their ability to inhibit the growth of several types of cancers of blood, skin, brain, colon, ovaries, breast, prostate and pancreas (Kawasaki BT et al., 2008). Subramaniam D et al., (2010) explain that Dietary phytochemicals have been shown to be effective in killing a variety of cancer cells in vitro, when used in pharmacologic concentrations. Qureshi MA et al., (1996) showed that SP or its extracts can prevent or inhibit cancer in humans and animals. Remirez D et al., (2002) reported that during oxidative stress, changes occur in NADPH activity, resulting in differences in the conformation of enzymes involved in the mitochondrial respiratory chain, nitric oxide synthase, xanthine dehydrogenase thereby generating high levels of superoxide. This leads to apoptosis, cardiac remodeling due to chronic pressure overload, atrial fibrillation etc.The effect of bilirubin and biliverdin on NADPH oxidase activity is mimicked by a phytochemical phycocyanobilin, which is a homolog of bileverdin. Analytical methods for profiling compounds in spirulina responsible for antioxidation, allowed a complete characterization of chemical and biochemical mechanisms of action ( Rasool $M$ and Sabina EP,2009). This could be explained by the antioxidant potential of spirulina ( Trushina EN et al., 2007). Nie S et al., (2007) reported that In many cases, the surface of nanoparticles has to be highly hydrophilic and able to prevent protein adsorption. With hydrophilic groups such as hydroxyl, carboxyl, and amino groups, most natural polysaccharides can attach to biological tissues (mainly epithelia and mucous membranes) via noncovalent bonds. Nanoparticles functionalized with bio adhesive polysaccharides could prolong residence time and therefore increase absorption of the loaded drugs (Liu $\mathrm{Z}$ et al., 2008).Although nanoparticles tend to accumulate in cancer cells through passive targeting process, this passive strategy has limitations due to its nonspecific delivery mode. However, when nanoparticles are functionalized with polysaccharides, polysaccharide moieties can interact specifically with the biological targets, e.g., lectins that have been found in the surface of tumor cells and malignant tissues (Lotan $\mathrm{R}$ and Raz A, 1988). Therefore, surface decoration of nanomaterial by polysaccharides could enhance cellpermeating and cancer-targeting abilities (Liu Z et al., 2008). Yip et al., (2006) reported that $\mathrm{CTAB}$ belongs to a group of quaternary ammonium compounds, which also includes benzethonium chloride and dequalinium chloride, both of which have demonstrated anticancer properties in vitro and in vivo by targeting tumor mitochondria. Yip KW et al., 2006, Weiss $\mathrm{MJ}$ et al ., 1987, Bleday $\mathrm{R}$ et al., 1986reported that CTAB belongs to a group of quaternary ammonium compounds, which also includes benzethonium chloride and dequalinium chloride, both of which have demonstrated anti-cancer properties in vitroand in vivoby targeting tumor mitochondria . Giraud I et al., 2004 demonstrated that Quaternary ammonium derivatives have also been reported to show enhanced anti-tumor activity compared totheir parent compounds, suggesting that molecules possessing quaternary ammonium moieties may be highly effective anti-cancer agents. Doxorubicin (DOX) in particular is often the first choice to treat mammary cancer. Nevertheless, its use has been limited due to the rapid development of chemo resistance and cardiomyopathic side effects (Wang J et al., 2011). The therapeutic activity of DOX results from its intercalating into DNA, thereby inhibiting topoisomerase II and preventing DNA and RNA synthesis (Deavall DG et al., 2012). Liu LL et al., 
(2007) reported that DOX's use in chemotherapy has been limited largely due to its diverse toxicities, including cardiac, renal, pulmonary, hematological and testicular toxicity. DOX-induced changes in the kidneys of rats include increased glomerular capillary permeability and glomerular atrophy. Although the exact mechanism of DOX-induced nephrotoxicity remains unknown, it is believed that the toxicity is mediated through free radical formation, irondependent oxidative damage of biological macromolecules, and membrane lipid peroxidation.

\section{CONCLUSION}

The findings of the present study demonstrated that Polysaccharide spirulina and $\mathrm{ZnO}$ nanoparticles treatment provided an effective protection against mammary carcinogenesis induced by $\mathrm{MNU}$ in rats, since these compounds were able to ameliorate serum biochemical parameters, enzymatic and non-enzymatic antioxidant defense system and to prevent the lipid peroxidation in these tissues.

\section{ACKNOWLEDGMWNT}

Special Thanks for Center of Excellence in Scientific Research (CESR), fac. of vet. Med. Benha Univ. that funded by management supporting excellence (MSE) and Benha University.

\section{REFERENCES}

Banchroft, J.D., Stevens, A., Turner, D.R. 1996. Theory and practice of histological techniques. Fourth Ed. Churchill Livingstone, New York, London, San Francisco, Tokyo.

Beutler, E., Duron, O., Kelly, B.M. 1963. Improved method for the determination of blood glutathione. J Lab Clin Med. 61:882-888.

Bleday, R., Weiss, M.J., Salem, R.R., Wilson, R.E., Chen, L.B., Steele, G., Jr. 1986. Inhibition of rat colon tumor isograft growth with dequalinium chloride. Arch Surg. 121: 1272-1275.

Chamorro, G., Abraham, S.K., Santhiya, S.T. 2004. Protective effect of Spirulina fusiformis on chemical-induced genotoxicity in mice. Fitoterapia. 75:2431.

Chen, L.B. 1988. Mitochondrial membrane potential in living cells. Annu Rev Cell Biol. 4:155-181.

Chen, S.H., Nickel, U., Ren, X.M. 1995. Fluorescence of $\mathrm{ZnO}$ ultrafine particles quenched by naphthothiacarbocyanine dye in ethanol: the effect of water. J. Colloid Interface Sci. 176: 286-292.

Cohen, N.A., Lai, S.Y., Ziober, A.F., and Ziober, B.L. 2004. Dysregulation of hypoxia inducible factor-1alpha in head and neck squamous cell carcinoma cell lines correlates with invasive potential. Laryngoscope. 114:418-423.

Cho, K., Wang, X., Nie, S., Chen, Z., Shin, D. 2008. Therapeutic Nanoparticles for Drug Delivery in Cancer, Clinical Cancer Research. 14(5):1310.

Deavall, D.G., Martin, E.A., Horner, J.M., Roberts, R. 2012. Drug-induced oxidative stress and toxicity. J Toxicol. 45:610-618.

Dumitrescu, R.G., Cotarla, I. 2005. Understanding breast cancer risk -where do we stand in 2005? J Cell Mol Med. 9: 208-221.

Ferrari, M. 2005. Cancer nanotechnology: opportunities and challenges, Nature Reviews Cancer. 5: 161.

Geraki, K., Farquharson, MJ. 2001. An X-ray fluorescence system for measuring trace element concentrations in breast tissue. Radiation Physics and Chemistry. 61:603-605.

Ghosh, A., Das, S.K., Biswas, J.R., Tripathi, H.S., Banerjee, G. 2000. The effect of $\mathrm{ZnO}$ addition on the densification and properties of magnesium aluminate spinel. Ceram. Int. 26: 605-608.

Giraud, I., Rapp, M., Maurizis, J.C., Madelmont, J.C. 2002. Synthesis and in vitro evaluation of quaternary ammonium derivatives of chlorambucil and melphalan, anticancer drugs designed for the chemotherapy of chondrosarcoma. J Med Chem. 45: 21162119. 
Huang, X., El-Sayed, I. H., Qian, W., El-Sayed, M. A. 2006. Cancer Cell Imaging and Photothermal Therapy in the NearInfrared Region by Using Gold Nanorods, Journal of the American Chemical Society. 128: 2115.

Isa, A.Y., Ward, T.H., West, C.M., Slevin, N.J., Homer, J.J .2006. Hypoxia in head and neck cancer. Br J Radiol 79:791-798.

Kaji, T., Fujiwara, Y., Inomata, Y. 2002. Repair of wounded monolayers of cultured bovine aortic endothelial cells is inhibited by calcium spirulan, a novel sulfated polysaccharide isolated from Spirulina platensis. Hayashi T. Life Sci. 70:1841-8.

Kawasaki, B.T., Hurt, E.M., Mistree, T., Farrar, W.L. 2008. Targeting cancer stem cells with phytochemicals. Mol Interv. 8:17484.

Kumari, A., Yadav, S.K., Yadav, S.C. 2010. Biodegradable polymeric nanoparticles based drug delivery systems. Colloids Surf B Biointerfaces. 75(1): 1-18.

Lee, R., Woo, W., Wu, W.B., Kummer, A., Duminy, H. and Xu, Z. 2003. Zinc accumulation in N- methyl-Nnitrosourea-induced rat mammary tumors is accompanied by an altered expression of ZnT-1 and metallothionein. Exp Biol Med. 228:689-696.

Lee, S., Simpson, M., Nimmo, M., and Xu, Z. 2004. Low zinc intake suppressed Nmethyl-N- nitrosourea-induced mammary tumorigenesis in SpragueDawley rats. Carcinogenesis. 25(10):1879-1885.

Liu, LL., Li, Q.X., Xia, L., Li, J., Shao, L. 2007. Differential effects of dihydropyridine calcium antagonists on doxorubicininduced nephrotoxicity in rats. Toxicology. 231: 81-90.

Liu, Z., Jiao, Y., Wang, Y., Zhou, C., Zhang, Z. 2008. Polysaccharides-based nanoparticles as drug delivery systems. Adv Drug Deliv Rev. 60(15): 1650 1662.

Lotan, R., Raz, A. 1988. Lectins in cancer cells. Ann N Y Acad Sci. 551: 385-398.

Mahmoud, Zhang, J., Ma, D., Izquierdo, R., V. 2012. Truong,"Optically-enhanced performance of polymer solarcells with low concentration of goldnanorods in the anodic buffer layer, Organic Electronics. 13(12): 3102.
Marcì, G., Augugliaro, V., López-Muñoz, M.J., Martín, C., Palmisano, L., Rives, V., Schiavello, M.,Tilley, R.J.D., Venezia, A.M. 2001. Preparation characterization and photocatalytic activity of polycrystalline $\mathrm{ZnO} / \mathrm{TiO} 2$ systems. 2 . Surface, bulk characterization, and 4nitrophenol photodegradation in liquidsolid regime. J. Phys. Chem. B. 105: 1033-1040.

Mehta, R.G., Murillo, G., Naithani, R., Peng, X. 2010. Cancer chemoprevention by natural products: How far have we come? Pharm Res. 27:950-61.

Melancon, K., Cheng, Q., Kiefer T.L., et al. 2005. Regression of MNU-induced mammary tumors with combination of melatonin and 9-cis-retinoic acid. Cancer Lett. 227: 39-48.

Mesbah, M., Dupuy, JF., Heutte, N., Awad L. 2004. Joint analysis of longitudinal quality of life and survival processes.Handbook ofStatistics: Advances in Survival Analysis, Vol. 23, Balakrishnan N, Rao C (eds). North Holland: Amsterdam.

Montgomery, H.A.C., Dymock, J. 1961. The determination of nitrite in water. Analyst. 86: 414-416.

Murray, Charles. 1984. Losing Ground: American Social Policy, 1950-1980. New York: Basic Books.

Nathanson, D. and Mischel, P. 2011. Charting the course across the blood-brain barrier, Journal of Clinical Investigation. 121: 31.

Nie, S., Xing, Y., Kim, G.J., Simons, JW. 2007. Nanotechnology applications in cancer. Annu Rev Biomed Eng 9:257-288.

Nishikimi, M., Appaji, N., Yagi, K.

1972. The occurrence of superoxide a nion in the reaction of reduced phenazine methosulfate and molecular o xygen. Biochem. Biophys. Res. Comm unication. 46: 849-854.

Omar, S., Khaled, H., Gaafar, R. 2003. Breast cancer in Egypt: a review of disease presentation and detection strategies. East Mediterr Health J. 9:448-57.

Paglia, D.E., Valentine, W.N. 1967. Studies on the quantitative and qualitative characterization of erythrocyte glutathione peroxidase. Lab Clin Med. 70:158-169. 
Parkin, D.M., Fernandez, LMG. 2006. Use of statistics to assess the global burden of breast cancer. Breast J. 12:S70-S80.

Perse, M., Cerar, A., Injac, R., Strukelj, B. 2009. N-nitrosomethylurea-induced breast cancer in rats, the histopathology of resulting tumors and its drawbacks as a model. Pathol. Encol Res. 15: 115-121.

Pissuwana, D., Valenzuela, S. M., Cortie, M. B. 2006. Therapeutic possibilities of plasmonically heated gold nanoparticles, Trends in Biotechnology. 24(2): 62.

Qureshi, MA., Garlich, JD., Kidd, MT. 1996. Dietary Spirulina platensis enhances humoral and cell-mediated immune functions in chickens. Immunopharmacol Immunotoxicol. 18:465-476.

Radhakrishnan Padmavathi, Palaniyandi Senthilnathan, Dechen Chodon, Dhanapal Sakthisekaran. 2006. Therapeutic effect of paclitaxel and propolis on lipid peroxidation andantioxidant system in 7,12 dimethyl benz (a) anthracene-inducedbreast cancer in female Sprague Dawley rats. Life Sciences. 78: $2820-2825$.

Rasool, M., Sabina, E.P. 2009. Appraisal of immunomodulatory potential of Spirulina fusiformis: an in vivo and in vitro study. J Nat Med. 63(2):169-175.

Remirez, D., Ledon, N., Gonzale, R. 2002. Role of histamine in the inhibitoryeffects of phycocyanin in experimental models of allergic inflammatory response. Med Inflamm. 11(2):81-85.

Robey, I.F., Lien, A.D., Welsh, S.J., Baggett, B.K., and Gillies, R.J .2005. Hypoxiainducible factor-1alpha and the glycolytic phenotype in tumors. Neoplasia. 7:324-330.

Ryter, S.W., Kim, H.P., Hoetzel, A. 2007. Mechanisms of cell death in oxidative stress. Antioxid Redox Signal 9:49-89.

Schrama, D., Reisfeld, R., Becker, J. C. 2006. Antibody targeted drugs as cancer therapeutics, Nature Reviews Drug Discovery. 5: p. 147.

Siddiqui, M.K., Jyoti, Singh, S., Mehrotra, P.K., Singh, K., Sarangi, R. 2006. Comparison of some trace elements concentration in blood, tumor free breast and tumor tissues of women with benign and malignant breast lesions, an Indian study. Environ Int. 32(5):630-7.

Sinha, A.K. 1972. "Colorimetric Assay of Catalase". Analytical Biochemistry.47: 389-394.

Subramaniam, D., Ramalingam, S., Houchen, C.W., Anant, S. 2010. Cancer stem cells. A novel paradigm for cancer prevention and treatment. Mini Rev Med Chem.103:59-71.

Thapliyal, R., Deshpande, S.S., and Maru, G.B. 2002. Mechanism(s) of turmericmediated protective effects against benzopyrenederived adducts. Cancer Letters. 175:79-88.

Tomatis, L. 2006. Role of experimental and epidemiological evidence of carcinogenicity in the primary prevention of cancer. Ann Ist Super Sanita. 42:11317.

Tomchenko, A.A., Harmer, G.P., Marquis, B.T., Allen, J.W. 2003. Semiconducting metal oxide sensor array for the selective detection of combustion gases. Sens. Actuators B. 93: 126-134.

Trushina, E.N., Gladkikh, O., Gadzhieva, Z.M., Mustafina, O.K., Pozdniakov, A.L. 2007. The influence of Spirulina and SelenSpirulina onsome indexes of rat's immune status Article Russian Vopr Pitan. 76(2):21-25.

Vincenzo, G. 2006. Breast cancer markers. Cancer Letters xx: 1-15.

Wang, J., Song, Y., Xu, S., Zhang, Q., Li, Y., Tang, D., Jin, S .2011. Down-regulation of ICBP90 contributes to doxorubicin resistance. Eur J Pharma. 656:33-38.

Weiss, M.J., Wong, J.R., Ha, C.S. 1987. Dequalinium, a topical anti-microbial agent, displays anticarcinoma activity based on selective mitochondrial accumulation. Proc Natl Acad Sci U S A. 84: 5444-5448.

Wu, Y.L., Tok, A.I.Y., Boey, F.Y.C., Zeng, X.T., Zhang, X.H. 2007. Surface modification of $\mathrm{ZnO}$ nanocrystals. Appl. Surf. Sci. 253: 5473-5479.

Yip, K.W., Mao, X., Au, PY., Hedley, D.W., Chow, S., Dalili, S., Mocanu, J.D., Bastianutto, C., Schimmer, A., and Liu, F.F. 2006. Benzethonium chloride: a novel anticancer agent identified by using a cell-based small-molecule screen. Clin Cancer Res. 12:5557- 5569. 